\title{
A Novel Conception to Diagnose Arhythmia by Monitoring Impulse of Radical Artery and Brachial Artery
}

\author{
Xu Han You MS* \\ Department of General Internal Medicine, China \\ *Corresponding author: Xu Han You MS, Department of General Internal Medicine, China
}

\begin{tabular}{|c|c|}
\hline ARTICLE INFO & ABSTRACT \\
\hline Received: 慧 February 16, 2021 & $\begin{array}{l}\text { While up to now, the best method to diagnose arhythmia has been being the } \\
\text { examination of standard electrocardiogram. Which the examination of standard }\end{array}$ \\
\hline Published: 慧 February 23, 2021 & $\begin{array}{l}\text { electrocardiogram is more complex than monitoring the impulse of radical artery and } \\
\text { brachial artery. So, a novel conception to diagnose arhythmia by monitoring impulse of }\end{array}$ \\
\hline
\end{tabular}

Citation: Xu Han You MS. A Novel Conception to Diagnose Arhythmia by Monitoring Impulse of Radical Artery and Brachial Artery. Biomed J Sci \& Tech Res Keywords: Radical Artery; Brachial Artery; Cardiac Impulse; Arhythmia; Diagnosis; Monitor; Translational Medicine

34(1)-2021. BJSTR. MS.ID.005506.

\section{Introduction}

As we all know that doctor always put the pulse of the patients as the important vital signs when they take physical examinations. Which the pulse must be record in the medical recordings. But in clinical practices, the most important thing is to know how the rhythm of heart is, apart from the pulse. Because how to understand the rhythm speedily and easily is directly related to the diagnosis and the prognosis result of emergency treatment, clinical management. While up to now, the best method to diagnose arhythmia has been being the examination of standard electrocardiogram. Which the examination of standard electrocardiogram is more complex than monitoring the impulse of radical artery and brachial artery. So, the novel conception has been created. That is why we do not to diagnose arhythmia by monitoring impulse of radical artery and brachial artery?

\section{The Facts and the Mechanism of Supporting the New Concept}

Though the conception is only an idea or a strategy. But there are lots of facts or experiences of clinical practices can support the creating of the conception. For the great inventions are usually created in the labor practices. As a doctor of internal medicine, when take physical examination bare handed or taking blood pressures by desktop mercury sphygmomanometer, the author can always know primarily the speed or slowness of the heartbeat, if the rhythm of heart is regularly, if the rhythm of heart is at the same strength and which class the arhythmia is. For example, when take physical examination bare handed or taking blood pressures by desktop mercury sphygmomanometer, the author can diagnose trigeminy, quadrigeminy, bradyarrhythmia, polycardia, the strength changes of heartbeat and possible atrial fibrillation. Which some most experienced doctors may also have the above-mentioned experiences.

\section{The Novel Technology in the Future}

As this conception goes on. The author thinks. By the modern computer, information, and related production technology, we can know how and what the rhythm of heart is by the easily and speedily way by monitoring the impulse of radical artery and brachial artery. While the fact is that the conception is only an idea or strategy. So, lots of basic and clinic research must be done before it can be applied into clinical practice.

\section{Challenges in Clinical Electrocardiography}

Researchers have found that the Clinical Electrocardiography is not in full power in diagnosing and treating cardiac diseases. As the JAMA Network has been publishing lots of articles about the challenges in clinical electrocardiography [1]. So, from this point of view, my novel conception technology is a future valuable technology. 


\section{Why the Conception and the Technology are Novel}

But It is exciting that up to now, the novel conception has not been being reported. Because by using Chinese key words or Chinese title of this letter to search in China National Knowledge Infrastructure, the biggest digital library in China in Knowledge

ISSN: 2574-1241

DOI: 10.26717/BJSTR.2021.34.005506

Xu Han You MS. Biomed J Sci \& Tech Res

(C) (i) This work is licensed under Creative

Submission Link: https://biomedres.us/submit-manuscript.php
Resource. Up to now, there has not been any report. And at the same time, by using English key words or title of this letter to search in PubMed. Up to now, there also has not been any report.

\section{References}

1. Challenges in Clinical Electrocardiography.

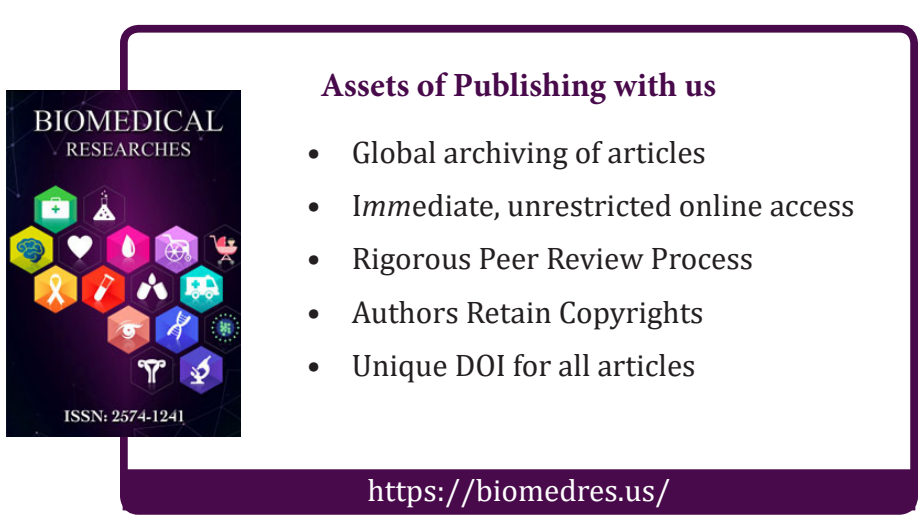

